\title{
Conscientious Objection and Moral Reform in Medical Education
}

ERIC J. KIM (D)

*Author affiliations can be found in the back matter of this article
凹

Levy

Library

Press

\section{ABSTRACT}

Whether the medical profession should accommodate conscientious objections (COs) remains an open question. I believe that doctors' COs should be accommodated only when they are derived from their commitments about the nature of medicine (i.e., no doctor qua doctor should perform the objected-to service), and that the medical profession ought to accommodate these COs in order to maintain a system-level capacity for moral progress and self-correction [1]. The purpose of this project is to explore how, if at all, my conception of Nature of Medicine COs and their reform-based argument for accommodation apply to medical education. Specifically, I consider two questions: 1) Should medical students be able to enter specialties (i.e., apply to the residencies) that provide the objected-to services; and 2) should medical students' COs be accommodated during their training?

While some have answered the first question in the negative [2], I argue that medical students should be able to enter the specialties relevant to their Nature of Medicine COs. As potential members of the medical profession, medical students lack the rights and privileges of its present members, but they are nonetheless pivotal in determining its future moral trajectory. If anti-euthanasia students were kept out of the relevant specialties (viz., palliative care or critical care), those fields would eventually fill with pro-euthanasia doctors. Importantly, policymakers (i.e., legislators and doctors who represent the medical profession) should and do give greatest consideration to those most affected by their policies - for euthanasia, patients and active doctors in relevant specialties. Doctors who are regularly expected to perform abortions, for example, should and do have more of a voice in the abortion debate than cardiologists or retired doctors do. The medical profession would therefore become less likely to change its potentially wrong stance. 
Again, not just any CO will fit the bill here; they must be based on a reasonable conception of medicine and its moral obligations. Such refusals speak to what doctors qua doctors cannot do - in this case, perhaps the principle that no doctor should end or assist in ending a human life unless it would end on its own (as with withdrawal of life support) or save another life (as with emergency abortions). Assuming that principle is reasonable (in the sense that it may indeed be true), the $\mathrm{CO}$ is universalizable and therefore the right kind of thing to drive policy reform. The alternative would be COs that are based on personal idiosyncrasies, such as one's religious beliefs, and would therefore not be universalizable. It would be inappropriate for such COs to drive policy reform, so my argument here would not protect them.

It follows from my conclusion about the first question that medical students' Nature of Medicine COs should be accommodated even before they become doctors. Otherwise, they might be so morally repulsed that they quit their medical education altogether. The specialties that provide the objected-to service would again fill with willing doctors, and the medical profession would find itself committed to potentially unethical policies. Importantly, this argument would fail if the empirical assumption that objecting students would quit were actually false. However, because of the United States' long history of CO accommodations, we lack the data to verify that assumption.

Ultimately, I wish to frame CO accommodations as a systemic feature of the medical profession that promotes moral self-correction, not a means of catering to the wishes of troublesome individuals. It follows from the need to maintain the profession's ability to reform that medical students' COs should be accommodated both during their training and when they decide which specialty to enter.

\section{COMPETING INTERESTS}

The author has no competing interests to declare.

\section{AUTHOR AFFILIATION}

Eric J. Kim (D) orcid.org/0000-0001-8032-2090

NYU Grossman School of Medicine, US

\section{REFERENCES}

1. Kim EJ, Ferguson K. Conscientious Objections, the Nature of Medicine, and the Need for Reformability. Bioethics. In submission.

2. Williams A. Conscientious Objection: A Medical Student Perspective. AMA Journal of Ethics. September 1, 2009; 11(9): 686-89. DOI: https://doi.org/10.1001/virtualmentor.2009.11.9.jdsc1-0909
TSMS Journal of Science

and Medicine

DOI: $10.29024 / \mathrm{ijsm} .34$
TO CITE THIS ARTICLE: Kim EJ. Conscientious Objection and Moral Reform in Medical Education. ISMMS Journal of Science and Medicine. 2021; 1(1): 1, pp. 1-2. DOI: https://doi. org/10.29024/ijsm.34

Submitted: 15 December 2020 Accepted: 15 December 2020 Published: 12 January 2021

COPYRIGHT:

(c) 2021 The Author(s). This is an open-access article distributed under the terms of the Creative Commons Attribution 4.0 International License (CC-BY 4.0), which permits unrestricted use, distribution, and reproduction in any medium, provided the original author and source are credited. See http://creativecommons.org/ licenses/by/4.0/.

ISMMS Journal of Science and Medicine is a peer-reviewed open access journal published by Levy Library Press. 